\title{
The conditioned Babkin reflex in human newborns'
}

\author{
Herbert Kaye \\ BROWN UNIVERSITY
}

\begin{abstract}
Abstraet
A study is reported which appears to obtain conditioned responding in the human newborn through the pairing of a recently discovered hand-mouth reflex with a kinesthetic conditioning stimulus. The procedure, which is short and does not require elaborate equipment, has potential usefulness as a test for differential conditionability of newborns.
\end{abstract}

\section{Introduction}

If pressure is exerted simultaneously on both palms of a supine newborn infant whose arms are held in a flexed position, the mouth opens (hereafter referred to as gaping) on a reflex basis. This reflex, first reported by Babkin in 1956 and later elaborated by Lippmann (1958) and by Parmelee (1963a), consists of a rapid mouth opening which is tonically maintained in a quiescent, but unsleeping, baby for several seconds when the palm pressure is maintained. It is often accompanied by rotation of the head toward the midline. It can be elicited with pressure on one palm in infants showing a strong two-palm reflex, but is most successfully demonstrated when the palm toward which the infant is facing is pressed. Most consistent results are obtained, moreover, from pressure applied across both the palm and the thenar eminence, rather than simply across the palm. Yawning often follows within $5 \mathrm{sec}$. of the release of pressure. The response tends to be inhibited in the sucking infant. The Babkin reflex, along with the palmomentalis reflex, has been noted in most apparently normal premature and full-term newborn infants (Parmelee, 1963b).

Some preliminary observations of the Babkin reflex in newborns led to the experimental design for the present study. It was noted that if the arms of the infant were moved from the extended to the flexed position several times just prior to pressing the palm, subsequent movement of the arms alone tended to elicit conditioned-like anticipatory mouth-opening responses. The following modification of the classical Pavlovian conditioning procedure was employed to study this apparently learned behavior.

\section{Method}

Twenty infants 48 to 96 hours of age were divided into two groups, 10 experimental Ss and 10 control. ${ }^{2}$ Experimental Ss received 5 trials of arm movement alone (Baseline), 35 trials of paired arm movement and palm-press (Conditioning), and 15 trials of arm movement alone (Test). Baseline and Test trials were accomplished by gripping the child gently at the wrists, moving his arms from the extended to the flexed position on either side of the head, holding approximately $3 \mathrm{sec}$, and then returning them to the extended position at his sides. During Conditioning trials the child was held across the palms, and the arms were raised in this manner. Pressure was applied when they reached the flexed position. Approximately $10 \mathrm{sec}$. elapsed between trials depending in part on the child's interim activity. Trials were not begun if the child was crying, yawning, or sucking. Although there was much of this behavior, it was generally confined to the first few second following the release of pressure. For the Control group, the Baseline period was followed by 35 trials of palm-press, while the infant's arms were maintained in the flexed position. This was followed by 15 trials of arm movement, again with 10 sec. intertrial intervals. Thus, in the Conditioning period the experimental group received 35 pairings of arm movements with palm-press, and the Control group received only palm-press. The gaping response was recorded by two observers. ${ }^{3}$ Agreement by both was required before the response was tallied.

\section{Results}

Figure 1 shows the number of responses, in blocks of 5 trials, during Baseline and Test for the two groups. Differences between the number of responses in Baseline were not significant $(t=1.34 ; d f=18 ; p>.10)$. For the 15 trials of Test, this statistic was highly significant $(t=3.56 ; \mathrm{df}=18 ; \mathrm{p}<.01)$. Within the Test trials, differences between groups were significant on trials $1-5$ $(t=2.61 ; d f=18 ; p<.02)$, and on trials $6-10(t=3.47$; $\mathrm{df}=18 ; \mathrm{p}<.01)$, but not for trials $11-15(\mathrm{t}=1.31$; $\mathrm{df}=18 ; \mathrm{p}>.10)$. Although the Baseline response rates were not significantly different, further statistical tests were made to assure that the reliability of the differences in Test trials did not result from the initial differences seen in Baseline, which would favor the experimental group. Each infant's Baseline response rate was subtracted from the mean of his rate for the first two blocks of Test trials. A t test between these two

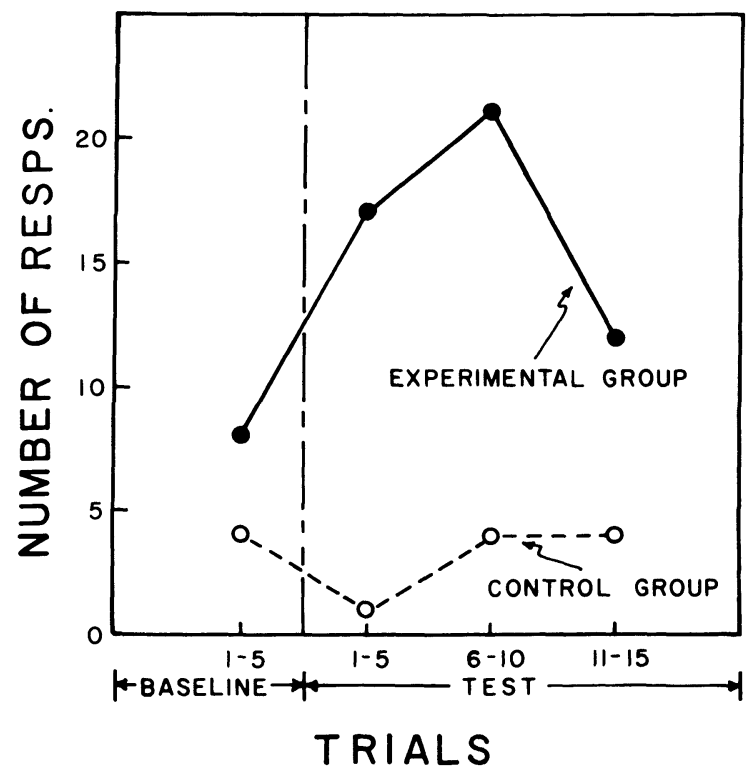

Fig. 1. Total number of "gaping" responses produced by the Experimental and Control groups during Baseline and Test arm movement trials. Each point represents the totals for 10 infants given 5 trials. 


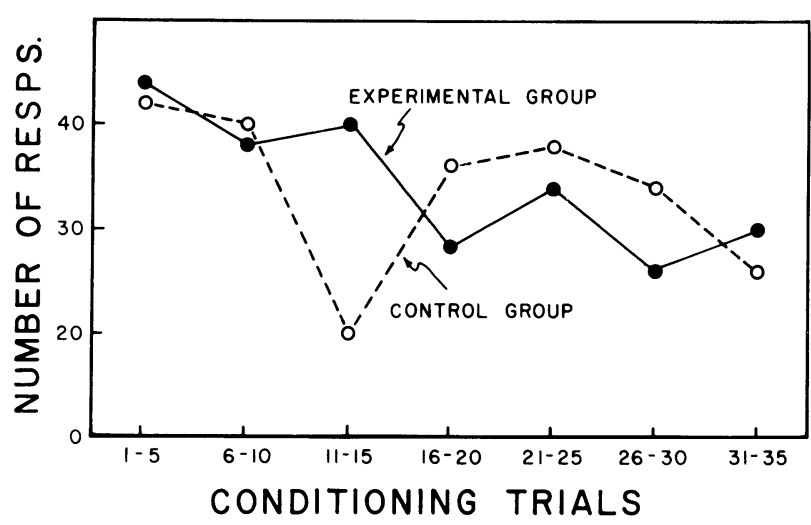

Fig. 2. Total number of "gaping" responses elicited during palm press conditioning and control periods. Each point represents the totals for 10 infants given 5 trials.

sets of scores was significant $(t=2.56 ; d f=18 ; p<.01)$, further supporting the difference found in the analysis of raw scores. Further examination of these difference scores indicated that the increase in response from the Baseline rate was significant for the experimental group $(t=2.72 ; d f=9 ; p<.05)$.

Figure 2 shows the number of unconditioned responses elicited from the two groups during the 35 trials of conditioning, or palm-press alone (for the control group) trials. An analysis of variance done over blocks of 5 trials as the within-Ss variable and treatments of groups as the between-Ss variable yielded no significant effects for groups, trials, or the groups-by-trials interaction. A related $t$ test done on differences in number of responses in the first and last 10 trials for all Ss did, however, show a significant decline $(t=2.51$; $\mathrm{df}=19 ; \mathrm{p}<.05)$. It would appear that habituation of this response is at best a slow process.

Following the inital examination of the data, an additional control group of 6 infants received 55 arm movements, comparable to the 55 arm movements administered to the experimental group. This control was instituted because the previous control had not received this number of arm-movements, and thus to assure that the increased responsiveness of the experimental group could not be attributed to this stimulation alone. The six Ss gave a total of only 3 responses in the 90 Test trials, and therefore no further Ss were added to this group.

\section{Diseussion}

It might be contended that this study does not involve conditioning since neither control group received both arm-movement and palm-press stimulation comparable to that of the experimental group. The usual pseudo- conditioning controls were not practical in this situation because of, (a) the relatively short intertrial interval, and (b) the necessity of switching from holding the wrists while raising the arms, to holding the palms while eliciting the reflex. Against the argument of increased arousal in the experimental group producing the conditioned-like effect, two Ss in the second control group (55 arm movements) were given an additional 35 trials of palm-press alone and 15 additional arm movement test trials, and neither showed any response during the Test. Another $\mathrm{S}$ in the second control group was given 35 paired arm movements and palm-press (as for the experimental group) after 55 arm movement trials and in a subsequent arm-movement test gave two conditioned responses in the first 5 trials.

More precise instrumentation of this conditionedBabkin procedure will be difficult, but the response shows promise for conditioning newborns who are conditionable. Other laboratory procedures for obtaining conditioning in the newborn are more elaborate and time consumming, requiring rather sophisticated instrumentation (Lipsitt \& Kaye, 1964; Marquis, 1931). The present test was accomplished within $15 \mathrm{~min}$. for each infant, and it may have clinical usefulness in a standard sensory and learning examination of the newborn. Referenees

BABKIN, P.S. The establishment of reflexactivity in early postnatal life. Central nervous system and behavior. Translations from the Russian Medical Literature. Josiah Macy Jr. Foundation and the National Science Foundation.

LIPPMANN, K. Uber den Babinschen Reflex. Arch. Kinderheilk., $1958,157,234-238$.

LIPSITT, L. P., \& KAYE, H. Conditioned sucking in the human newborn. Psychon. Sci., 1964, 1, 29-30.

MARQUIS, D. P. Can conditioned responses be established in the newborn infant? J. genet. Psychol., 1931, 39, 479-492.

PARMELEE, A. H., JR. The hand-mouth reflex of Babkin in premature infants. Pediatrics, 1963a, 31, 734-740.

PARMELEE, A.H., JR. The palmomental reflex in premature infants. Developmental medicine and child neurology, 1963b, 5, 381-387. Notes

1. This study was supported by a PHS research grant (NB 04268) to Dr. Lewis P. Lipsitt, Brown University. The author is indebted to Dr. Lipsitt for his critical reading of the manuscript.

2. The author thanks the staff of the Providence Lying in Hospital and the Child Development Study of the Institute for Health Sciences at Brown University for their help.

3. The author thanks Mrs. D. Westlake for her assistance as the second observer.

\section{Erratum}

BILODEAU, E. A., \& FOX, P. W. The NCR booklet: A group technique for studying word arousal phenomena as a function of S's idiosyncratic habits. Psychon. Sci., 1965, 2, 223-224.-The Editor regrets that the title was given incorrectly over the article and should read as stated above. 